\title{
Preparation of Tetanus toxoid for equine
}

\author{
H. A. EL-Helw*, M. M. Fayez, Roukaia M. Osman \\ Veterinary Serum and Vaccine Research Institute, Cairo, Egypt.
}

\begin{abstract}
Tetanus toxoid for equines has been prepared by cultivation of $C$. tetani into new synthetic medium for production of high potent tetanus toxin which gave high flocculation units [ 90 Lf (Limit of flocculation)], and high minimum lethal dose (MLD) $(600,000)$. Tetanus toxin was inactivated by formalin, and adsorbed on aluminum hydroxide gel as an adjuvant. It was inoculated into rabbits as a preliminary evaluation for its potency, showing the permissible units allowed to be used for vaccination of horse. The vaccine was tested in horses, which exhibited higher titer of specific antibodies persisted for 8 months post vaccination.
\end{abstract}

Tetanus is a fatal bacterial disease, and one of the most dramatic and globally prevalent diseases of humans and vertebrate animals, has been reported for over 24 centuries. The clinical manifestations occur as consequence of the release of an enormously potent neurotoxin secreted by an anaerobic spore-forming bacterium Clostridium tetani, whose nature habitat is soil, dust, and intestinal tracts of various animals (Bruggemann et al., 2003).

Horses are the most susceptible of all domestic animals, and the disease is fatal to more than 80 percent of affected horses due to its spore is harbor in soil for long times giving it a great chance to found its way to the body via any wounds especially deep lacerated wounds that caused by sharp objects penetration into the sole of the hoof. The incubation period varies from one to three weeks depending on the infective material introduced to the wound, anaerobic condition of the wound and care of the wound, the first signs being to progress by stiffness, lameness, a saw horse stance, inability to eat and spasms of the head muscles resulting in lock jaw (British Horse Society, 2004).

The production of tetanus toxin in high yield depends on several factors namely; presence of particular toxigenic factors in the culture medium, intrinsic toxigenic capacity of $C$. tetani strains, and mode of cultivation. Although the toxigenic factors are still identified, semi synthetic and synthetic media enable the production of tetanus toxin to varying degrees have been formulated. The most widely used classical media were described by (Mueller and Miller, 1954; Latham et al., 1962). More

* Corresponding author. Tel.: +20 0101022324 ; E-mail address: hamedelhelw@hotmail.com

(Hamed El- Helw) recently, formulation of new synthetic medium described by (EL-Helw, 2007), produced high potent tetanus toxin and more economic than traditional media.

As tetanus toxin induces death before an adaptive immunity could be generated, active immunization with tetanus vaccine is crucial for prevention of death. At present, protection is routinely induced through immunization with a tetanus toxin derivative, which was first described for more than 80 years ago. Tetanus toxin inactivated by formaldehyde (tetanus toxoid) is devoid of toxicity but is still highly immunogenic with a stabilized native conformation (Inic-Kanada et al., 2009).

Tetanus toxoid is very immunogenic and even soluble tetanus toxoid given in adequate dosage can be protective. It is common, that the toxoid is adsorbed to aluminum hydroxide or phosphate prior to immunization, since the presence of this adjuvant induces an increased immune response (Bizzini et al., 1984; Majgaard and Koch, 1988).

Parenteral injection of toxoid prepared from highly antigenic exotoxins of $C$. tetani regularly evokes neutralizing antitoxin, which is highly protective against the risk of disease in animals. The tetanus toxoid is among the most effective prophylactic immunogens in general use today. Regular vaccination of all horses and ponies against tetanus is absolute essential; in addition vaccination is quick simple and highly effective and only practical mean of long-term protection (British Horse Society, 2004).

The aim of this work was planned for preparation of tetanus toxoid to be used as safe and efficient vaccine for equine primarily, and for other domestic animals generally.

\section{Materials and methods}


Bacterial Strain. Lyophilized C. tetani (Harvard strain, 49205), was supplied by the Egyptian Organization for Biological Products and Vaccines, Tetanus Department, Giza, Egypt. It was used for preparation of tetanus toxoid.

Swiss Mice. Seven hundred Swiss mice were used for determination of the minimum lethal dose of produced tetanus toxin; $\mathrm{L}+$ dose of tetanus toxin, and antitoxin units in sera of vaccinated animals. These mice were obtained from Veterinary Serum and Vaccine Research Institute, Abassia, Cairo.

Rabbits. Ten New Zealand rabbits weighted about $2-2.5 \mathrm{~kg}$, were used for evaluation of the prepared tetanus toxoid, they were obtained from Veterinary Serum and Vaccine Research Institute.

Horses. Ten native breed horses, aged from 2436 months, weighted on an average of 330-360 $\mathrm{kg}$, obtained from Veterinary Serum and Vaccine Research Institute, were used for evaluation of prepared tetanus toxoid.

Vaccine preparation. Lyophilized $C$. tetani strain was reconstituted in Brain Heart Infusion Broth (Oxoid), supplemented with 0.5\% Yeast extract (Oxoid); $0.5 \%$ sodium chloride (Oxoid), and $2 \%$ glucose and $\mathrm{pH}$ adjusted to 7.4 and incubated at $37^{\circ} \mathrm{C}$ according to (Demain et al., 2005).

After reconstitution of lyophilized strain, three successive subcultures were done in the same medium, then inoculated in fermentation medium for production of tetanus toxin as described by (EL-Helw, 2007) from the third subculture, and incubated at $35^{\circ} \mathrm{C}$ for 8 days. The prepared toxin was assayed to determine its potency by flocculation test according to (WHO, 1997), and MLD according to (Ipsen, 1941). Formalin was added to prepared toxin in a percentage of $0.5 \% \mathrm{v} / \mathrm{v}$ to the culture medium, and then incubated for 21 days at $37^{\circ} \mathrm{C}$ for complete inactivation.

Sterility and safety tests were done to the prepared toxoid according to (British Pharmacopoeia, 2009).

After complete inactivation of tetanus toxin, the toxoid was separated from the culture medium by filtration using Millipore filter $(0.22 \mu \mathrm{m})$, then $0.5 \%$ glycine were added and $1 / 10,000$ thiomersal as preservative.

Aluminum Hydroxide gel at concentration of $20 \%(\mathrm{v} / \mathrm{v})$ was added to tetanus toxoid as an adjuvant.

The potency test. The potency of the final product was tested by inoculation of the vaccine in two doses via intramuscular with 21 days apart, assign ten New Zealand rabbits into 4 groups each of first three groups comprised of three, and the $4^{\text {th }}$ group one rabbit as control group. Groups $(1,2$, and 3) vaccinated with different doses of 1,3 , and $5 \mathrm{ml}$ respectively. Rabbits were bled after 14 days from $2^{\text {nd }}$ dose, then serum samples were separated and determination of antitoxin titer in samples by toxin neutralization test was done according to (Barile et al., 1970).

Vaccination of Horses. Ten male horses of native breed were vaccinated with tetanus toxoid aluminum hydroxide gel at dose of $5 \mathrm{ml}$ intramuscularly, twice with 21 days apart. Blood samples were obtained at intervals of 0 day (day of the $1^{\text {st }}$ dose inoculated), (21 days, 2 months, 3 months, 4 months, 6 months, and 8 months) post the $2^{\text {nd }}$ dose. The blood was allowed to clot and the serum was separated and assayed by toxin neutralization test.

\section{Results and Discussion}

The production of a high potent vaccine against tetanus depends mainly on production of high quality tetanus toxins. In this study a modified medium described by (EL-Helw, 2007), was used, in which casitone was a basal source of essential peptides and amino acids, brain heart infusion was used instead of heart infusion broth; yeast extract was added instead of vitamin B complex beside addition of potassium chloride. This medium yielded high significant production of tetanus toxin as evaluated by minimal lethal doses (MLD), which was found to be 600,000 MLD and by flocculation showing $\mathrm{Lf}$ : $90 \quad(\mathrm{Lf}=$ limit of flocculation) with $\mathrm{Kf}: 50(\mathrm{Kf}=$ time elapse until first tube make flocculation in minutes), in agreement with (Zacharias and Björklund, 1968), who found that the addition of potassium chloride doubled the amount of flocculation units where the potassium ions increase the permeability of cell membranes.

The evaluation of protection afforded against tetanus was based on the levels of tetanus antitoxin per $\mathrm{ml}$ of serum attained, with the level of 0.01 units per $\mathrm{ml}$, as determined by (Tasman and Huygen, 1962) being chosen as the minimum level of antitoxin necessary to afford protection against the manifestation of clinical tetanus.

As tetanospasmin is denaturated easily and rapidly (Bizzini, 1979), the effect of using different diluents of variable chemical nature on the potency of the toxin must be put in 
consideration. The results of this work showed that the use of $1 \%$ peptone and $0.2 \%$ gelatin as diluents for evaluated toxin were the best diluents as both verified any minute amount of the toxin in the filtrate and retained its lethal effect till a dilution of $1: 320,000 / \mathrm{ml}$. Accordingly, it can be concluded that salt solutions free from proteins (phosphate-buffed saline) were unfavorable for tetanospasmin dilution. This agrees with the observation of (Pound, 1970) who found that the addition of certain lipids or proteins to tetanus toxin or culture filtrates appeared to enhance the action of the toxin on mice.

It was recorded that each milliliter of serum should contains not less than 10 units of tetanus antitoxin if rabbits are used or 30 units if guinea pigs are used for evaluation of the potency of tetanus vaccine for Equines (British pharmacopeia, 2009). The results obtained from titration of vaccinated rabbits sera as shown in Table (1) revealed that the mean tetanus antitoxin titer in sera of vaccinated rabbit was 12 $\mathrm{IU} / \mathrm{ml} \pm 1.88$ in respective to the dose of $5 \mathrm{ml}$ of tetanus toxoid, so this dose cover the permissible requirement allows for production of vaccine, where upon used this dose for vaccination of horses.

The results of titration vaccinated horse sera as showed in Table (2) demonstrate good immune responses after the second dose, which appeared very rapidly, and reached to the peak titer (32 IU/ml) after 21 days from second dose. It is also clear that there is a significant decline in tetanus antitoxin titer after 90 days from the second dose $(10 \mathrm{IU} / \mathrm{ml})$ although this sharp decline in antitoxin it is able to protect horses against the disease. These results parallel to those obtained in other studies on responses to tetanus toxoid injections into horses, (Liefman, 1977), demonstrating that the individual variation in immune response to primary dose was such that while in horses received sufficient stimulus to afford protection for several months, the immune responses was sufficiently strong in some horses to afford 12 months later. The strong immune response resulting from the second dose ensured protection for at least 8 months in all horses studied. A third dose of the toxoid gives in that time or earlier at 6 months would probably provide lifelong immunity, but as there is no evidence to support this statement, regularly booster doses should be considered.

From the results obtained in this study it could be concluded that using of the new synthetic medium is essential for production of highly potent tetanus toxoid. The vaccine induces good immune response against tetanus up to eight months after vaccination of horses. So it could be a recommendation to use this vaccine for regular vaccination of domestic animals particularly equines for long-terms protection against tetanus.

Table (1): Antitoxin titer of rabbits vaccinated with different doses of Tetanus toxoid.

\begin{tabular}{ccc}
\hline Group & Dose & Antitoxin titer expressed in IU/ml \\
\hline $\mathbf{1}$ & $1 \mathrm{ml}$ & $4 \pm 0.7$ \\
$\mathbf{2}$ & $3 \mathrm{ml}$ & $8 \pm 0.8$ \\
$\mathbf{3}$ & $5 \mathrm{ml}$ & $12 \pm 1.88$ \\
$\mathbf{4}$ & Control & 0 \\
\hline
\end{tabular}

Table (2): Mean tetanus antitoxin titer in sera of vaccinated horses.

\begin{tabular}{cccccccc}
\hline \multirow{2}{*}{$\begin{array}{c}\text { Horse } \\
\text { No. }\end{array}$} & \multicolumn{6}{c}{ Tetanus antitoxin titer IU/ml in sera of horses after vaccination with the 2nd dose of } \\
Tetanus toxoid \\
\cline { 2 - 8 } & Prevaccination & $\mathbf{2 1}$ days & $\mathbf{6 0}$ days & $\mathbf{9 0}$ days & $\mathbf{1 2 0}$ days & $\mathbf{1 8 0}$ days & $\mathbf{2 4 0}$ days \\
\hline $\mathbf{1}$ & 0 & 30 & 10 & 6 & 3 & 2 & 0.5 \\
$\mathbf{2}$ & 0 & 32 & 14 & 9 & 3 & 2 & 0.5 \\
$\mathbf{3}$ & 0 & 34 & 17 & 13 & 6 & 2 & 0.5 \\
$\mathbf{4}$ & 0 & 30 & 14 & 8 & 2 & 1 & 0.5 \\
$\mathbf{5}$ & 0 & 29 & 13 & 11 & 4 & 3 & 0.5 \\
$\mathbf{6}$ & 0 & 33 & 15 & 12 & 4 & 3 & 1 \\
$\mathbf{7}$ & 0 & 34 & 18 & 12 & 5 & 4 & 1 \\
$\mathbf{8}$ & 0 & 36 & 19 & 13 & 5 & 2 & 0.5 \\
$\mathbf{9}$ & 0 & 32 & 17 & 7 & 4 & 2 & 0.5 \\
$\mathbf{1 0}$ & 0 & 30 & 14 & 9 & 4 & 2 & 0.5 \\
Mean & 0 & $32 \pm 2.26$ & $15.1 \pm 2.68$ & $10 \pm 2.53$ & $4 \pm 1.15$ & $2.3 \pm 0.82$ & $0.6 \pm 0.21$ \\
\hline
\end{tabular}


Fig (1): Mean tetanus antitoxin titer in sera of vaccinated horses.

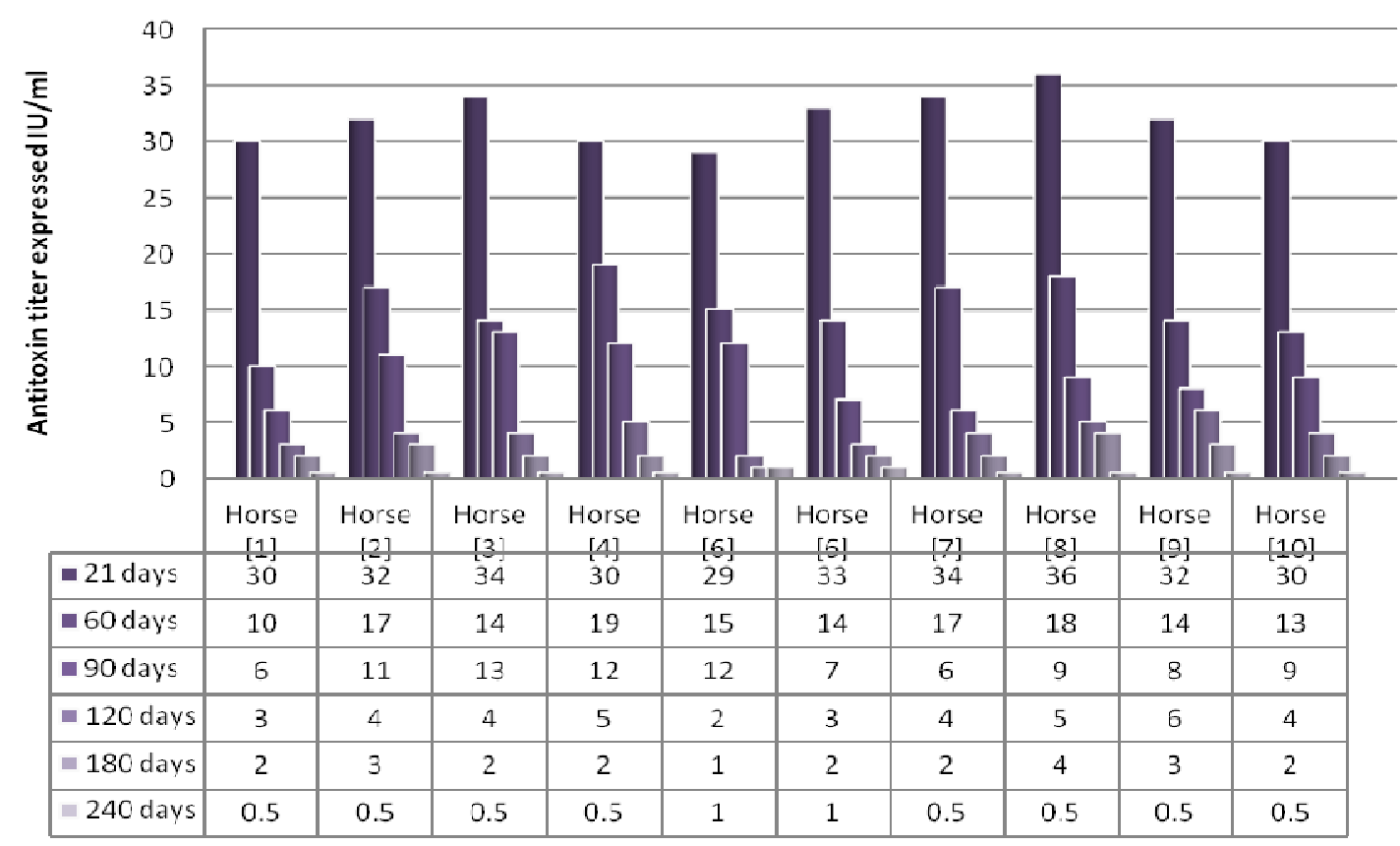

\section{References}

Barile, M. F.; Hardegree, M. C. and Pittman, M. (1970): Immunization against neonatal tetanus in New Guinea. 3 The toxin-neutralization test and the response of guinea pigs to the toxoids as used in the immunization schedules in New Guinea. Bull. WHO, 43: 453-459.

Bizzini, B. (1979): Tetanus Toxin. Microbiol. Rev., 43: 224-240.

Bizzini, B. (1984): Tetanus. Academic Press, New York.

British Horse Society (2004): Advise on tetanus \& Influenza vaccination for horses and ponies. Retrieved from http://www.horsetrust.org.uk/pdfs/horsehealth/vaccination. pdf

British Pharmacopoeia (Eds.) (2009): Clostridium tetani vaccines, (Veterinary suppl.) (p.233). ISBN: 9780113227990 .

Bruggemann, H.; Baumer, S.; Fricke, W. F.; Wiezer, A.; Liesegang, H.; Decker, I.; Herzberg, C.; Martinez-Arias, R.; Merkl, R.; Henne, A. and Gottschalk, G. (2003): The genome sequence of Clostridium tetani, the causative agent of tetanus disease. Proc. Natl. Acad. Sci., 100(3):13161321.

Demain, A. L.; Gerson, D. F. and Fang, A. (2005): Effective levels of tetanus toxin can be made in a production medium totally lacking both animal (e.g. brain heart infusion) and dairy proteins or digests (e.g. casein hydrolysates). Vaccine, 23(46-47), 5420-5423.

EL-Helw, H. A. (2007): A New medium for production of the tetanus toxin. J. Egypt. Vet. Med. Assoc., 67(1):125131.

Inic-Kanada, A. B.; Stojanovic, M. M.; Zivkovic, I. P.; Petrusic, V. Z. and Dimitrijevic, L. A. (2009): The monoclonal antibody 26 raised against tetanus toxoid also recognizes tetanus toxin and B2- glycoprotein I- its binding properties in vitro and potential applications. J. Serb. Chem. Soc., 74(3):245-257.

Ipsen, J. (1941): Die Auswertung des direkten Giftwertes des Tetanusgiftes ab Beispiel der biomathematischan Ausnutzung der Absterbedauer. Arch. Exp. Pathol. Pharmacol., 197:536-549.

Latham, W. C.; Bent, D. F. and Levine, L. (1962): Tetanus toxin production in the absence of protein. Appl. Microbiol., 10:146-152.

Liefman, C. E. (1977): "Active and passive immunization of the horse against tetanus ." M. V. Sc. Thesis, Univ. of Melbourne, Melbourne.

Majgaard-Jensen, O. and Koch, C. (1988): On effect of Aluminum hydroxide as an immunological adjuvant. APMIS, 7:249

Mueller, J. H. and Miller, P. A. (1954): Variable factors influencing the production of tetanus toxin. J. Bacteriol., 67:271-274.

Pound, A. W. (1970): The influence of certain lipids and proteins on the effect of tetanus toxin in mice. J. Med. Microbiol., 3:411-426.

Tasman, A. and Huygen, F. J. A. (1962): Bull. Wld. Hlth Org., 26:397

WHO (1997): A WHO guide to good manufacturing practice (GMP) requirements global programme for vaccine and immunization vaccine supply and quality, global training network. Retrieved from www.who.int/vaccinesdocuments/DocsPDF/www9666.pdf.

Zacharias, B. and Björklund, M. (1968): Continuous production of Clostridium tetani toxin. Appl. Microbiol., 16(1): 69-72.

\section{تحضير توكسيد التيتانوس للفصيلة الخيلية}

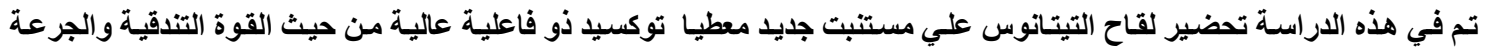

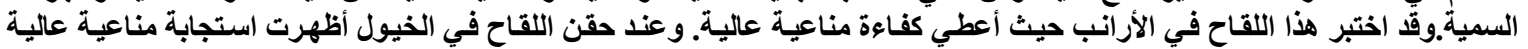

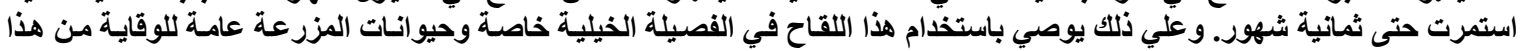

